American Journal of Applied Sciences 9 (6): 842-845, 2012

ISSN 1546-9239

(C) 2012 Science Publications

\title{
The Effect of the Configuration of the Screw Fixation on the Interfragmentary Strain
}

\author{
Boonthum Wongchai \\ Department of Mechanical Engineering, Faculty of Engineering at Si Racha, \\ Kasetsart University, 199 M.6, Tungsukhla, Si Racha, Chonburi, 20230, Thailand
}

\begin{abstract}
Problem statement: The interfragmentary strain $\left(\varepsilon_{\mathrm{IF}}\right)$ is the important parameter for femur fracture healing. The Dynamic Compression Plate (DCP) is commonly used in femur fracture. The DCP and the fractured femur are fixed by using the conventional screws. Approach: This research is proposed to investigate the effect of configuration of the screw fixation on the interfragmentary stain by using Finite Element Analysis (FEA), eight configurations of the screw fixation with the body load of 400 and 500 N. Results: The experimental results show that the relation of $\varepsilon_{\mathrm{IF}}$ and screws are the polynomial equations. Conclusion: We can decrease the interfragmentary strain by adding the number of screw with the groups of screw configuration.
\end{abstract}

Key words: Interfragmentary strain, dynamic compression plate, femur fracture, finite element

\section{INTRODUCTION}

Fractures of human femur are one of most frequent bone fractured. The middle points of the femur is critical point because of the maximum bending moments occur at this point. Internal fixation devices are directly applied to the fractured femur. The boneplate is commonly used in femur fracture. The Dynamics Compression Plate (DCP) and the Locking Compression Plate (LCP) are two types of favorite bone-plates.

The DCP and the fractured femur are fixed by using the conventional screws and generate compression force between the DCP and the femur. Conventional screw cannot lock with the DCP hole (Kanchanomai et al., 2008; Field et al., 2004). LCP hole is developed to solve this problem. We can use both types of screw with the LCP hole, the locking screw and the conventional screw. The distance between the fractured femur and the LCP can generate when using the locking screw and the compression force can generate when using the conventional screw (Miller and Goswami, 2007; Stoffel et al., 2003; Ahmad et al., 2007).

When the fracture occurs at the middle part of the femur, the physician will cut the fracture and form a gap of 1-10 mm.

The interfragmentary strain $\left(\varepsilon_{\mathrm{IF}}\right)$ is defined as the ratio of the fracture gap displacement after the body load applied and the original fracture gap as show in Fig. 1.

The Eq. 1 of IFS is:

$\varepsilon_{\mathrm{IF}}=\frac{\Delta \mathrm{L}}{\mathrm{L}}$

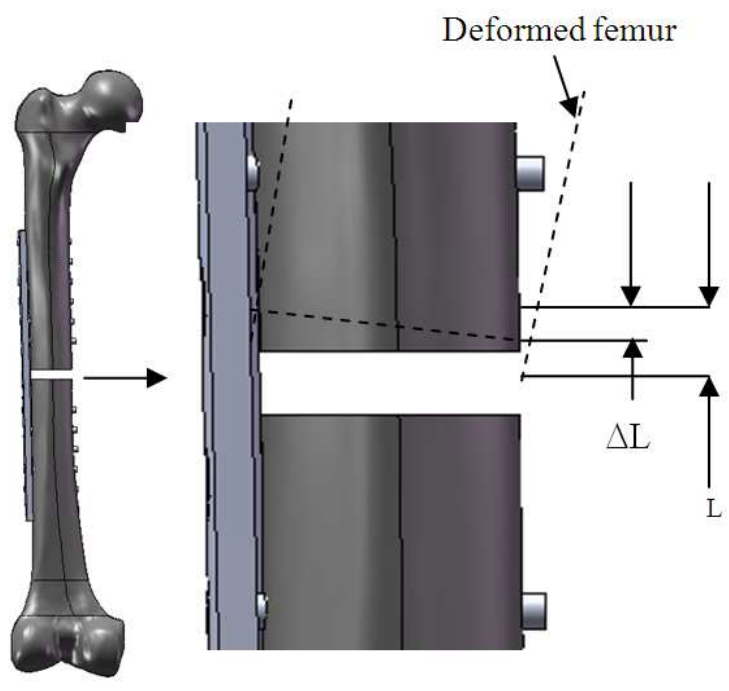

Fig. 1: The deformation of the fractured femur

Where:

$\Delta \mathrm{L}=$ The fracture gab displacement after the body load (W) applied

$\mathrm{L}=$ The original fracture gap length

The best IFS ranges from 2-10\% (Perren, 1979; Kim et al., 2010).

\section{MATERIALS AND METHODS}

Finite Element Analysis (FEA): The third generation femur of Pacific Research Lab, the 14-hole DCP and the 12 screws are assembled by using SolidWorks 2007 as show in Fig. 1 and 2. 
Am. J. Applied Sci., 9 (6): 842-845, 2012

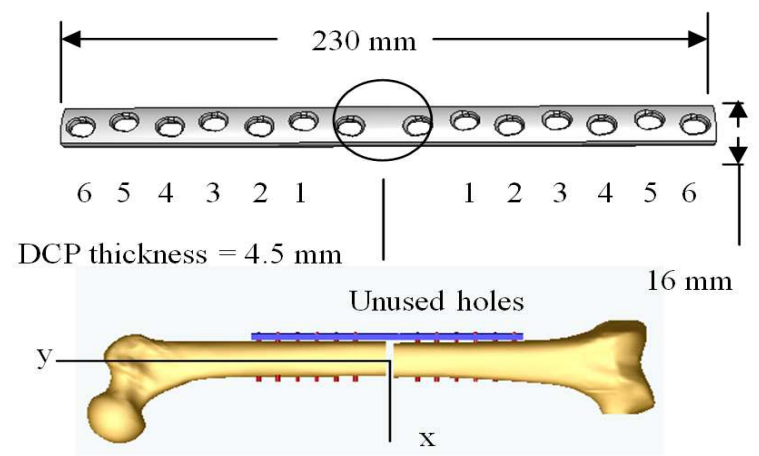

Fig. 2: The hole-number of the DCP

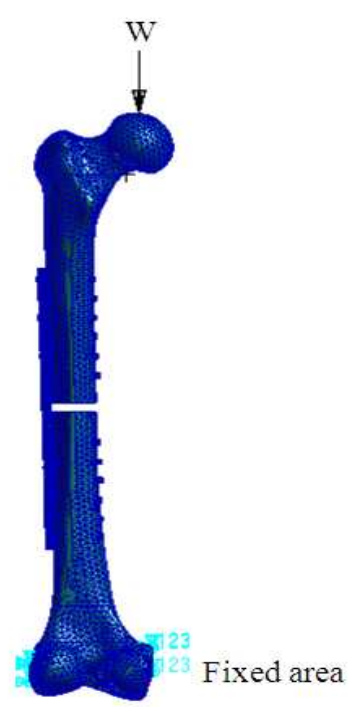

Fig. 3: Boundary condition of the finite element models

Table 1: The screw configurations on each side

\begin{tabular}{|c|c|c|}
\hline Model & Fixed at hole-number & Number of screws \\
\hline 1 & 123456 & 6 \\
\hline 2 & 13456 & 5 \\
\hline 3 & 456 & 4 \\
\hline 4 & 56 & 3 \\
\hline 5 & 1 & 2 \\
\hline 6 & 12 & 3 \\
\hline 7 & 123 & 4 \\
\hline 8 & 12346 & 5 \\
\hline
\end{tabular}

Table 2: The groups of screw configuration

\begin{tabular}{lll}
\hline Group & Model & Number of screws \\
\hline 1 & 54321 & 23456 \\
2 & 56781 & 23456 \\
\hline
\end{tabular}

Table 3: Material properties

\begin{tabular}{lcl}
\hline & Young's modulus (GPa) & Poission's ratio \\
\hline SS & 210.0 & 0.3 \\
Cortical bone & 17.0 & 0.3 \\
Cancelous & 0.7 & 0.2 \\
\hline
\end{tabular}

Table 4: Types of the contact surfaces

\begin{tabular}{lll}
\hline Surface1 & Surface2 & Type \\
\hline DCP & Screw & Glue \\
DCP & Cortical femur & Touch \\
Screw & Cortical femur & Glue \\
Screw & Cancelous femur & Glue \\
Cortical femur & Cancelous femur & Glue \\
\hline
\end{tabular}

The Pacific research laboratories bone models are usually used in biomechanics research (Stoffel et al., 2003; Wongchai, 2011). The assembled model is imported to MSC.Patran $2008 \mathrm{r} 1$ for construct the finite element model. The 4-node tetrahedral is used.

The screw configurations: The fractured femur was bridged by the 14-hole DCP as shown in Fig. 2. The 10$\mathrm{mm}$ fracture gab and the $4.5-\mathrm{mm}$ diameter screws are used in the model. Two screws were fixed at 1 st and 6th holes on both sides. The other holes are fixed with additional screws. Two holes at the middle are left without any screws.

The eight configurations of screw fixation are shown in Table 1.

Two groups of screw configuration are conducted by using the direction of the screw fixation as shown in Table 2. The number of screws varies from 2-6.

Material properties: The DCP and screw are made of Stainless Steel (SS). Material properties of the DCP, screw, cortical bone and cancelous bone are shown in Table 3 (Stoffel et al., 2003; Fouad, 2010).

Boundary condition: The femur head is acted by the body load $\mathrm{W}$. We obtain the fracture gab Length (L) of $10 \mathrm{~mm}$. We fixed the lowest area of the femur in the finite element models as show in Fig. 3. There are many contact surfaces. Types of the contact surfaces are show in Table 4.

The finite element models from MSC.Patran 2008 r1 is solved by using MSC.Marc for nonlinear finite element problems.

\section{RESULTS}

The results of the fracture gab displacements are shown in Table 5.

From the fracture gab displacement in Table 5 we can determine $\varepsilon_{\mathrm{IF}}$ by using Eq. 1 as shown in Table 6 .

The displacement of the femur from FEA is shown in Fig. 4.

From the groups of screw in Table 2 and the results in Table 6, we represent $\varepsilon_{\mathrm{IF}}$ versus the number of screws $(\mathrm{N})$ in Fig. 5-8. 
Am. J. Applied Sci., 9 (6): 842-845, 2012
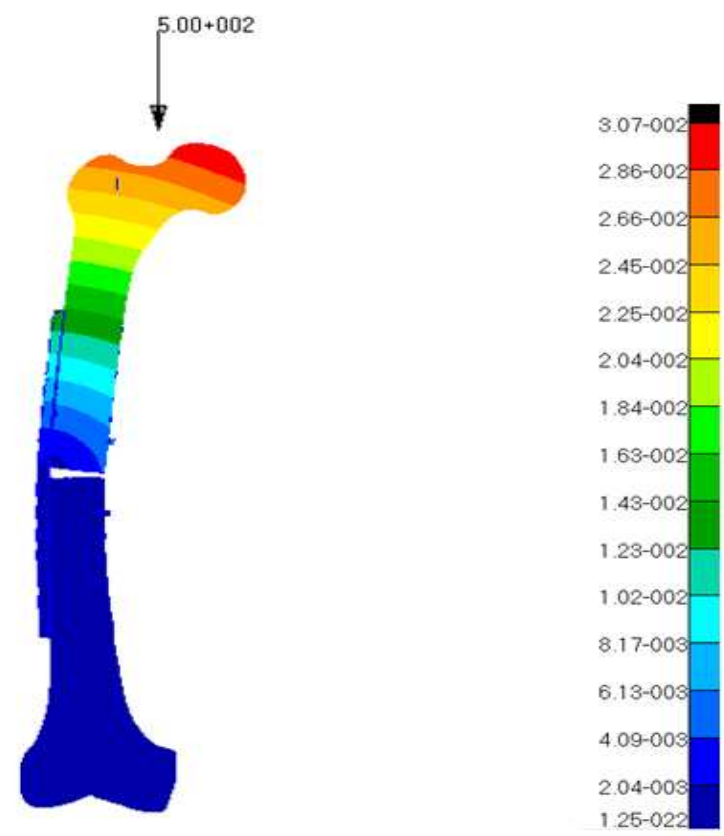

Fig. 4: The displacement of the femur

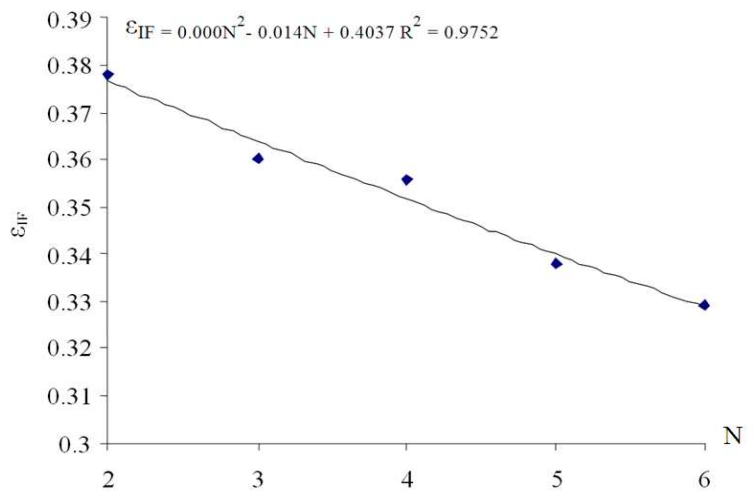

Fig. 5: $\varepsilon_{\mathrm{IF}}$ versus the number of screws (400 $\mathrm{N}$ groups 1$)$

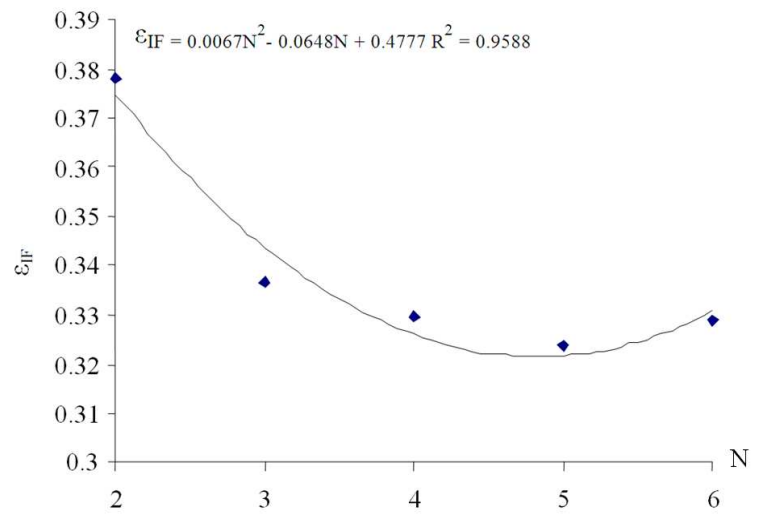

Fig. 6: $\varepsilon_{\mathrm{FF}}$ versus the number of screws (400 $\mathrm{N}$ groups 2$)$

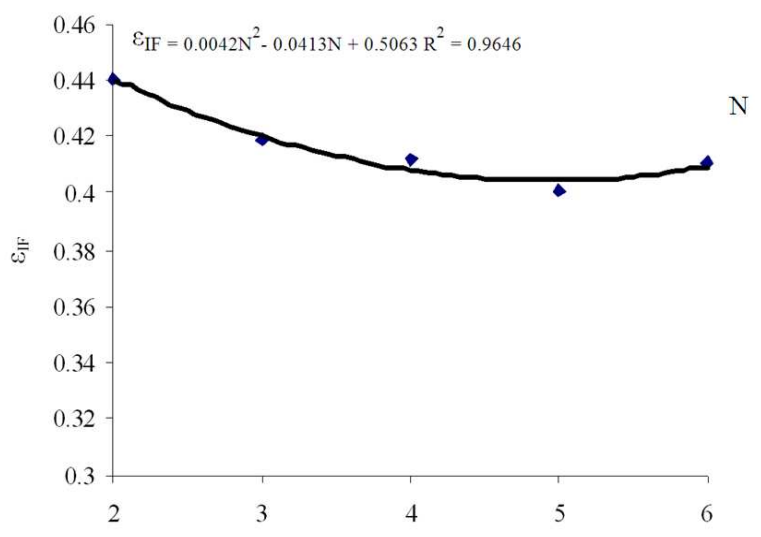

Fig. 7: $\varepsilon_{\mathrm{FF}}$ versus the number of screws (500 $\mathrm{N}$ groups 1$)$

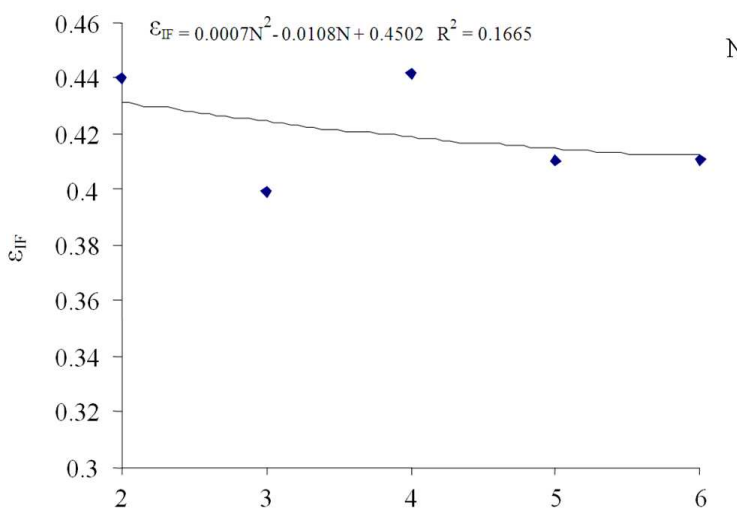

Fig. 8: $\varepsilon_{\mathrm{IF}}$ versus the number of screws (500 $\mathrm{N}$ groups 2$)$

Table 5: The fracture gab displacement

\begin{tabular}{lll}
\hline Model & $\begin{array}{l}\text { Body load } 400 \mathrm{~N} \\
\Delta \mathrm{L}(\mathrm{mm})\end{array}$ & $\begin{array}{l}\text { Body load } 500 \mathrm{~N} \\
\Delta \mathrm{L}(\mathrm{mm})\end{array}$ \\
\hline 1 & 3.290 & 4.106 \\
2 & 3.380 & 4.007 \\
3 & 3.559 & 4.118 \\
4 & 4.179 & 4.189 \\
5 & 3.778 & 4.404 \\
6 & 3.366 & 3.993 \\
7 & 3.296 & 4.412 \\
8 & 3.237 & 4.098 \\
\hline
\end{tabular}

Table 6: The inter fragmentary strain

\begin{tabular}{lll}
\hline & \multicolumn{2}{c}{$\varepsilon_{\mathrm{IF}}$} \\
Model & Body load 400 N & Body load 500 N \\
\hline 1 & & \\
2 & 0.3290 & 0.4106 \\
3 & 0.3380 & 0.4007 \\
4 & 0.3559 & 0.4118 \\
5 & 0.4179 & 0.4189 \\
6 & 0.3778 & 0.4404 \\
7 & 0.3366 & 0.3993 \\
8 & 0.3296 & 0.4412 \\
\hline
\end{tabular}




\section{DISCUSSION}

The graphs of $\varepsilon_{\mathrm{IF}}$ and number of screws are the polynomial equations with $\mathrm{R}^{2}>0.95$ except in case of $\mathrm{W}$ $=500 \mathrm{~N}$ and the group of screw configuration is group 2. The results show that the values of $\varepsilon_{\mathrm{IF}}$ are decreased by adding the number of screws.

\section{CONCLUSION}

We could decrease the interfragmentary strain by adding the number of screw with the groups of screw configuration.

\section{REFERENCES}

Ahmad, M., R. Nanda, A.S. Bajwa, J. Candl-Couto and S. Green 2007. Biomechanical testing of the locking compression plate: When does the distance between bone and implant significantly reduce construct stability? Injury, 38: 358-364. DOI: 10.1016/j.injury.2006.08.058

Field, J.R., R. Edmonds-Wilson and R.M. Stanley, 2004. An evaluation of interface contact profiles in two low contact bone plates. Injury, 35: 551-556. DOI: $10.1016 / \mathrm{S} 0020-1383(03) 00215-8$

Fouad, H. 2010. Assessment of function-graded materials as fracture fixation bone-plates under combined loading conditions using finite element modelling. Med. Eng. Phys., 33: 456-463. DOI: 10.1016/j.medengphy.2010.11.013
Kanchanomai, C., V. Phiphobmongkol and P. Muanjn, 2008. Fatigue failure of an orthopedic implant - A locking compression plate. Eng. Failure Anal., 15: 521-530. DOI: 10.1016/j.engfailanal.2007.04.001

Kim, S.H., S.H. Chang and H.J. Jung, 2010. The finite element analysis of a fractured tibia applied by composite bone plates considering contact conditions and time-varying properties of curing tissues. Compos. Struct., 92: 2109-2118. DOI: 10.1016/j.compstruct.2009.09.051

Miller, D.L. and T. Goswami, 2007. Review of locking compression plate biomechanics and their advantages as internal fixators in fracture healing. Clin. Biomech., 22: 1049-1062. DOI: 10.1016/j.clinbiomech.2007.08.004

Perren, S.M., 1979. Physical and biological aspects of fracture healing with special reference to internal fixation. Clin. Orthopeadics Related Res., 138: 175-196. PMID:376198

Stoffel, K., U. Dieter, G. Stachowiak, A. Gachter and M.S. Kuster, 2003. Biomechanical testing of the LCP - how can stability in locked internal fixators be controlled? Injury, 34: 11-19. DOI: 10.1016/j.injury.2003.09.021

Wongchai, B., 2011. Stress prediction in the dynamic compression plate with changing the configuration of the screw fixation. J. Comput. Sci., 7: 466-470. DOI: $10.3844 /$ jcssp. 2011.466 .470 